\title{
Cervical Spine Surgery
}

\section{An Historical Perspective}

\author{
Vincenzo Denaro MD, Alberto Di Martino MD, PhD
}

Published online: 7 January 2011

(C) The Association of Bone and Joint Surgeons (B) 2011

\begin{abstract}
Background Continued innovation in surgery requires a knowledge and understanding of historical advances with a recognition of successes and failures.

Questions/purposes To identify these successes and failures, we selectively reviewed historical literature on cervical spine surgery with respect to the development of (1) surgical approaches, (2) management of degenerative disc disease, and (3) methods to treat segmental instability. Methods We performed a nonsystematic review using the keywords "cervical spine surgery" and "history" and "instrumentation" and "fusion" in combination with "anterior approach" and "posterior approach," with no limit regarding the year of publication. Used databases were PubMed and Google Scholar. In addition, the search was extended by screening the reference list of all articles. Results Innovative surgical approaches allowed direct access to symptomatic areas of the cervical spine. Over the years, we observed a trend from posterior to anterior surgical techniques. Management of the degenerative spine has evolved from decompressive surgery alone to the direct removal of the cause of neural impingement. Internal fixation of actual or potential spinal instability and the associated instrumentation have continuously evolved to
\end{abstract}

Each author certifies that he or she has no commercial associations (eg, consultancies, stock ownership, equity interest, patent/licensing arrangements, etc) that might pose a conflict of interest in connection with the submitted article.

V. Denaro, A. Di Martino $(\square)$

Department of Orthopaedics and Trauma Surgery, University

Campus Bio-Medico of Rome, Via Alvaro del Portillo,

200, 00128 Rome, Italy

e-mail: a.dimartino@unicampus.it allow more reliable fusion. More recently, surgeons have developed the basis for nonfusion surgical techniques and implants.

Conclusions The most important advances appear to be (1) recognition of the need to directly address the causes of symptoms, (2) proper decompression of neural structures, and (3) more reliable fusion of unstable symptomatic segments.

\section{Introduction}

Current surgical approaches for treating cervical spine diseases have developed through the continuous innovations in surgical approaches, bone grafting techniques, and instrumentation. Rapid advances in imaging, minimally invasive techniques, and nonfusion technologies suggest we are at a threshold for a new era in patient care. However, few technologies or their applications are entirely new, as developers work within the framework of past experience [63].

Continuing innovation requires a knowledge and understanding of past advances, the ability to recognize successes and mistakes, and the vision to clarify current and future challenges. While many innovations and surgical techniques have been proposed, some have been abandoned over time. It is reasonable to examine this experience and inquire into what lessons can be derived, given cervical spine surgery includes some of the most successful operations in surgery (eg, single-level cervical discectomy and fusion) [24], and some crucial advances should be kept in mind to improve current technology and practice.

We therefore performed a selective historical review on cervical spine surgery with respect to the development of 
(1) surgical approaches, (2) management of degenerative disc disease, and (3) methods to treat segmental instability.

\section{Search Strategy and Criteria}

We performed a nonsystematic search using the keywords "cervical spine surgery" and "history" and "instrumentation" and "fusion" in combination with "anterior approach" and "posterior approach," with no limit regarding the year of publication. Used databases were PubMed and Google Scholar. Given our linguistic capabilities, we considered publications in English, Spanish, French, Portuguese, and Italian. All journals were considered. These searches yielded 215 articles. Article search included both reviews and original papers. Based on the abstract, we excluded 192 articles we judged irrelevant because they were unrelated to the topic. In addition, the search was extended by screening the reference list of all the remaining articles. This added 65 articles. Finally, analysis of books at the historical section and regular section of the library of our institution led to the retrieval of 15 additional papers.

\section{Surgical Approaches}

Innovative surgical approaches have made surgery of the cervical spine more feasible. In general, we observed a trend from posterior to anterior exposures favoring surgical techniques. At the beginning of the last century, surgeons were mainly involved with the treatment of complications of Pott's disease, namely deformity and drainage of abscesses, and later with management of neoplastic invasion and iatrogenic instability of the cervical spine after laminectomy procedures. Contemporaneously, surgeons began to perform surgery in patients with cervical spine fractures and other common causes of cervical instability or nerve palsies. As an example, in 1907, Codivilla [17] (Fig. 1) described the treatment of a nerve root compression due to impingement by the transverse processes of the fourth and fifth cervical vertebrae in a patient with a previous cervical compression fracture at $\mathrm{C} 4-\mathrm{C} 5$. He removed the transverse apophysis and freed a nerve root adherent to the bony callus and obtained a complete resolution of the C5 nerve root paralysis.

Posterior approaches to the spine were the first to be described most likely because the spinous processes of the vertebrae are easy to palpate and the posterior aspects of the spine more superficial. Anterior approaches developed independently from spinal surgery to address nonspinal diseases. The transbuccal approach, for example, was at first described by Auffret in 1896 to gain access to the posterior wall of the pharynx and subsequently used to drain tuberculosis abscesses [11]. The anterior mandible, tongue, and pharynx splitting approach was described by Kocker [49] as early as 1911, where it was used to access the upper part of the pharynx for tumors and abscesses arising from that region. Crowe and Williams used the transoral approach to review an osteoma in 1944 [78], and
Fig. 1A-B (A) A photograph of Alessandro Codivilla with his signature is shown. (B) The cover of the book by Vittorio Putti on the writings of Alessandro Codivilla is shown. Images courtesy of the Historical Section of the Library of the University Campus BioMedico of Rome. Reprinted with permission of Licinio Cappelli Editore from Putti V, ed. Scritti medici di Alessandro Codivilla. Pubblicati dall'Istituto Ortopedico Rizzoli. Vol Archivio ed atti della società italiana di chirurgia. XX adunanza, 1907. Bologna, Italy: Licinio Cappelli Editore; 1907.
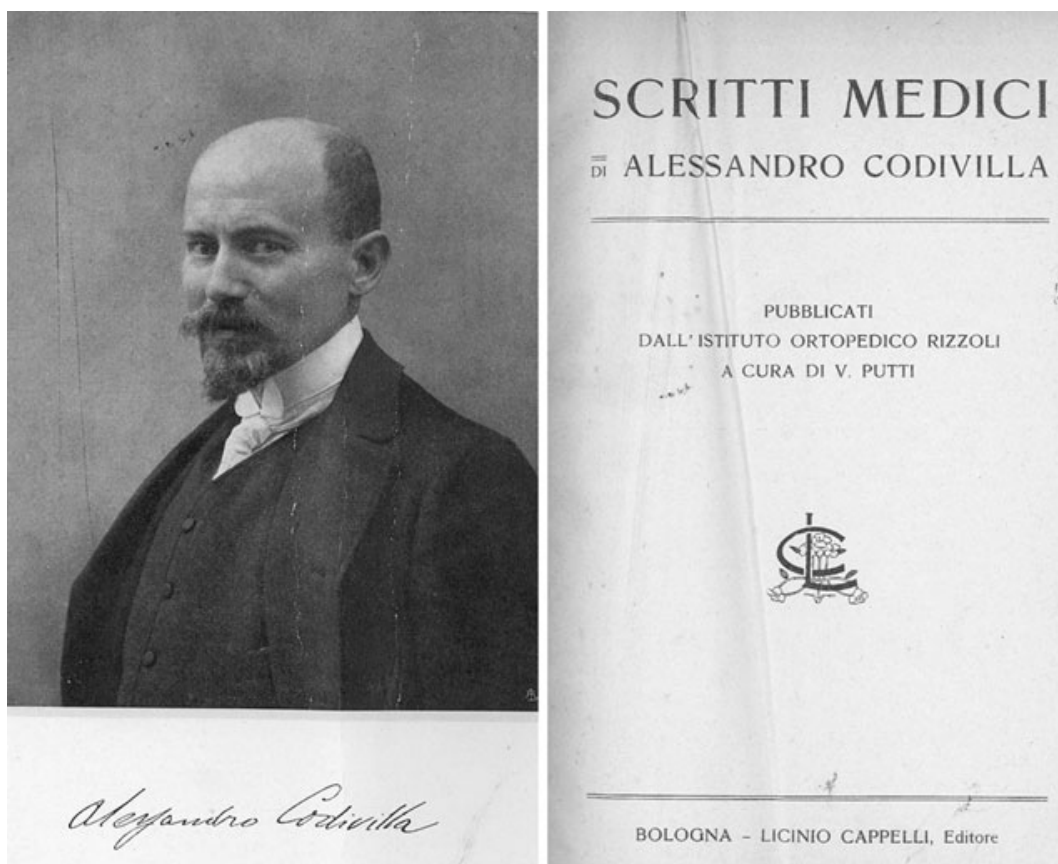

A

B 
in 1962, Fang and Ong used a similar approach to treat six patients with $\mathrm{C} 1-\mathrm{C} 2$ instability due to injury. Fang and Ong were the first to describe the severe intraoperative and postoperative complications of this surgical approach, being mainly infections. Only the widespread use of antibiotics allowed a more extensive use of this approach. Henry [38] in 1957 described a presternocleidomastoid approach (retropharyngeal and retrocarotid) to obtain surgical access to the vertebral artery and transverse apophyses, intertransverse foramina, and nerve roots up to the cervicooccipital region. This approach to the upper cervical spine was also later described by Whiteside and Kelly [84] in 1966. Anterolateral approaches (the high presternocleidomastoid approach, retropharyngeal and precarotid) were first described by Smith and Robinson [77] in 1958. Cloward [16] described a similar approach later that year, referring to the paper of Smith and Robinson. Similar later reports were made by De Ande and MacNab [19] in 1969 and Riley [62] in 1973.

\section{Cervical Disc Herniation and Degenerative Spinal Stenosis}

Laminectomy (or hemilaminectomy) was long the preferred technique for decompressing degenerative conditions at the cervical spine, such as protrusions of the intervertebral disc, frank disc herniations, and spinal stenosis. The advent of the anterior approach and surgical techniques to the cervical spine offered the surgeons the ability to directly address the pathologic processes that primarily originated from the anterior spine. As a result, anterior approaches are generally preferred when the pathology is anterior.

At the beginning of last century, surgeons treated herniated discs like tumors arising in the spine that required removal. The treatment of vertebral exostoses was first proposed by Gowers [35] in 1892. In 1905, Walton and Paul [83] performed posterior explorations for "neoplasms" of the cervical spinal cord with negative findings. One of the two reported patients died a few days later. At autopsy, the spinal cord was deeply indented anteriorly by an extradural mass that arose from the sixth intervertebral space, presumably a herniated disc [83]. (This article is reproduced in this issue as a Classic.) Elsberg [26] described a cervical laminectomy from the fifth to the seventh segment to remove a "chondroma" in a 57-year-old man who had a 10-week history of progressive quadriparesis. Stookey [79] later reported a group of cervical extradural chordomas, which he removed via hemilaminectomy. In 1932, Peet and Echols [61] performed histologic studies of such specimens and proposed these chondromas were actually a protrusion of the intervertebral disc. Between
1929 and 1932, Schmorl, Junghans, and Andrae described the anatomic and pathologic aspects of intervertebral disc protrusion from the spinal columns, but the concept of chondroma persisted for some time [9]. Brain and Wilkinson [9] in 1952 described a series of 45 patients with compression of the spinal cord (38 patients) or nerve roots (seven patients). They suggested the primary lesion was degeneration of the intervertebral disc and distinguished acute lesions due to herniation of the nucleus pulposus and chronic lesions arising from degenerative spondylosis [9].

Owing to the growing knowledge of disc herniations at the lumbar spine, surgeons then began using decompression for treating cervical disc herniations [29]. Scaglietti described such surgery in 1949 on a woman with C6-C7 disc herniation presenting with severe neck pain and signs of numbness of the first three fingers, absence of the triceps reflex, and severe muscle atrophy [30]. The surgery was performed through a posterior approach and consisted of a hemilaminectomy, root decompression, and removal of the herniated disc. Postoperatively, the patient wore a Minerva cast for 1 month. The authors reported a 16-year followup with complete resolution of symptoms.

Laminectomy has been performed using several variations of technique. Between the 1950s and 1960s, Rogers [67] opened the dura and sectioned the dentate ligaments after laminectomy (Fig. 2). This maneuver was used to improve retraction of the spinal cord by decreasing tension
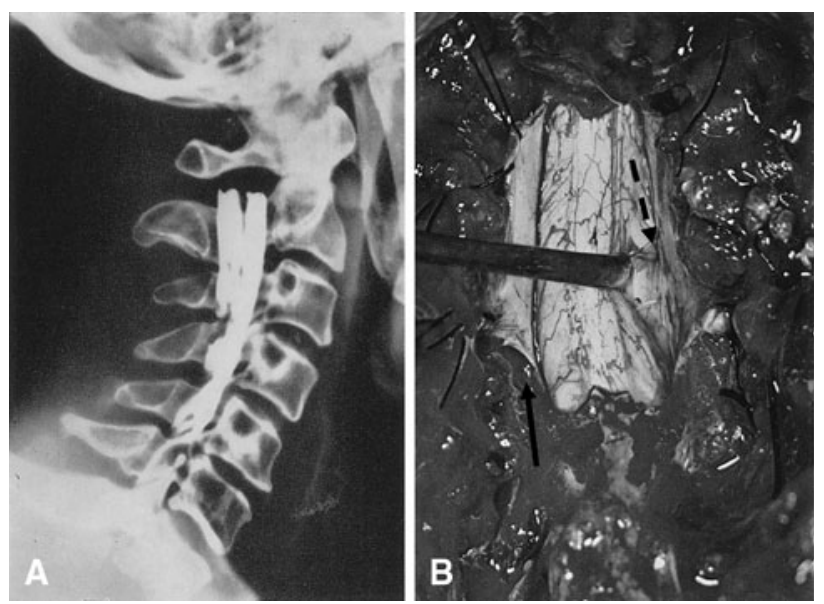

Fig. 2A-B (A) A lateral radiographic myelogram shows compression from C5-C6 cervical disk herniation. (B) A photograph of the operative field is shown after laminectomy, opening of the posterior aspect of the dura (solid arrow), and section of the dentate ligaments. After retraction of the spinal cord with a probe, it is possible to appreciate the prominence of the herniated disc (dashed arrow). Removal of the hernia occurred via an extradural approach. Reprinted with the kind permission of the Società Italiana di Ortopedia e Traumatologia from Fineschi G. Clinica e terapia delle protrusioni del tratto cervicale. Paper presented at Atti $51^{\circ}$ congresso della Società Italiana di Ortopedia e Traumatologia: Le protrusioni posteriori del disco intervertebrale. October 22-25, 1966; Catania, Italy. 
and allowed the surgeon to identify and excise the posterolaterally herniated disc [46]. Alternatively, excision of the disc herniation was also performed via an extradural approach after foraminotomy and freeing of the nerve root [10], with sacrifice of a nerve root $[29,30]$, or by opening of the root sleeve and by sectioning of the denticulate ligaments (Frykholm's surgery) [32]. These approaches were generally abandoned with the advent of techniques to decompress the spine from anteriorly.

Increasing knowledge in pathophysiology and biomechanics of the cervical spine strongly influenced changes in surgical approach to diseases at the cervical spine. The studies of spinal biomechanics were begun during the two world wars, particularly World War II, where the introduction of high-performance aircraft introduced the need for spinal column injuries biomechanics studies; at the same time, studies on the properties of the intervertebral disc were performed [56]. One of the pioneers in this era was Carl Hirsch, a Swedish orthopaedic surgeon who performed spinal biomechanical studies in the 1940s and strongly influenced a generation of young surgeons [56]. Another pioneer of modern biomechanics was Lysell [52], who in 1969 reported a comprehensive in vitro study of cervical spine motion and patterns of motion.

In the 1950s, surgeons began to shift from using posterior to anterior techniques. The first report of anterior cervical fusion performed for symptoms of cervical spondylosis appeared in 1955 [64]. Robinson and Smith [64] suggested disc degeneration led to osteophyte formation, disc narrowing and subluxation, instability of one cervical vertebra on another, or disc protrusion, the pathologic change-producing symptoms. Their original paper reported on their first eight patients, with short followup. They further reported the results of their first 55 patients in 1962 [66]. In 1958, Cloward [16] reported on the use of his instrumentation to achieve interbody fusion. He modified instruments designed for posterior interbody fusion at the lumbar spine by developing instrumentation that allowed drilling a circular hole in the intervertebral disc space and the insertion of a cylindrical dowel of bone. Cloward's initial report consisted of 47 patients, 27 with neurologic compromise and 20 with severe pain; four had myelopathy. Graft resorption and nonunion occurred in three of the 47 patients, and one sustained spinal cord injury at the time of surgery. A year later, Scoville questioned Cloward's technique by suggesting the possibility of accelerated adjacent segment degeneration [75]. However, this suggestion was not frequently debated in the literature until the late 1970s [7]. It continues to be an important issue today and is one of the major justifications for the development of arthroplasty implants designed to preserve motion [24].

Seeking alternatives to anterior decompression and/or fusion, Fernström [28] in 1966 described implantation of a cervical arthroplasty device in a human to try to reproduce the "ball joint" mechanism of the disc and maintain segmental motion. He presumed a stabilizing effect could be achieved on the neighboring vertebrae that would be equivalent to a fusion but without fusing the disc space; the issue of adjacent-disc degeneration was evidently not considered rationale for the implant. His endoprosthesis was shaped like a metal ball bearing, which he inserted into the disc space of both lumbar and cervical areas. The prostheses were 6 to $10 \mathrm{~mm}$ in diameter. A total of 191 prostheses were implanted in 125 patients at the cervical, thoracic and lumbar spine at single and multiple levels; of these, 13 cervical implants were used in eight patients. In radiographic evaluations at 4 to 7 years postoperatively, $74 \%$ of his patients had moderate disc space narrowing due to subsidence of the stainless steel balls into the vertebral body. Despite his pioneering attempts, Fernström himself described hypermobility, subsidence, and above all migration and abandoned the use of this device. McKenzie [54] examined 103 patients who underwent Fernström intervertebral disc replacement. After an average followup time of 17 years, he found only one of 155 prostheses had to be removed in this population. After the development of lumbar arthroplasty devices in 1980s, enthusiasm for cervical arthroplasty devices was renewed, and in 1989, the Department of Medical Engineering at Frenchay Hospital, Bristol, United Kingdom, began the initial design process for an artificial cervical joint, leading to implants used in clinical studies in 1991 [18]. The initial design was a twopiece, stainless steel, metal-on-metal, ball-in-socket configuration with anteriorly placed anchoring screws. The results of the first human trial with this cervical prosthesis ("Cummins-Bristol" artificial cervical joint) were reported in 1998 [18]. Since then, several cervical spine arthroplasty implants have been marketed and implanted with various results in terms of relief of patients' disease and prevention of degeneration at the adjacent disc, but long-term results are still not available [24].

Cervical spinal stenosis at multiple levels has also been managed over the years by an anterior or posterior route, with the aim to widen the spinal canal [8]. Boni and Denaro in 1969 developed the technique called multiple subtotal corpectomies [6]. Since then, this technique has been modified and simplified to decrease the rate of possible complications $[8,22]$. The technique was called "multiple" because it is performed at multiple levels, "subtotal" because the lateral walls of the vertebral body were preserved, and "corpectomy" because the central part of the vertebral body was fully removed. The original technique, as described by Boni and Denaro, required modified Cloward instrumentation at multiple levels and then widening of the holes at the multiple levels and deepening of the bony trench with removal of the posterior walls of the 
Fig. 3A-C (A) A preoperative myelogram shows spondylosis and myelopathy of $\mathrm{C} 3-\mathrm{C} 4, \mathrm{C} 4$ $\mathrm{C} 5$, and C5-C6 in a 62-year-old man. (B) A myelogram shows the spine 12 years after multiple-level decompression and fusion had been performed in 1969. (C) The anterior aspect of the posterior longitudinal ligament is exposed and covered with Surgicel $^{\mathbb{R}}$ (Ethicon, Inc, Somerville, NJ). Reprinted with the kind permission of Springer Science + Business Media from Boni M, Denaro V. The cervical stenosis syndrome with a review of 83 patients treated by operation. Int Orthop. 1982;6:185-195.
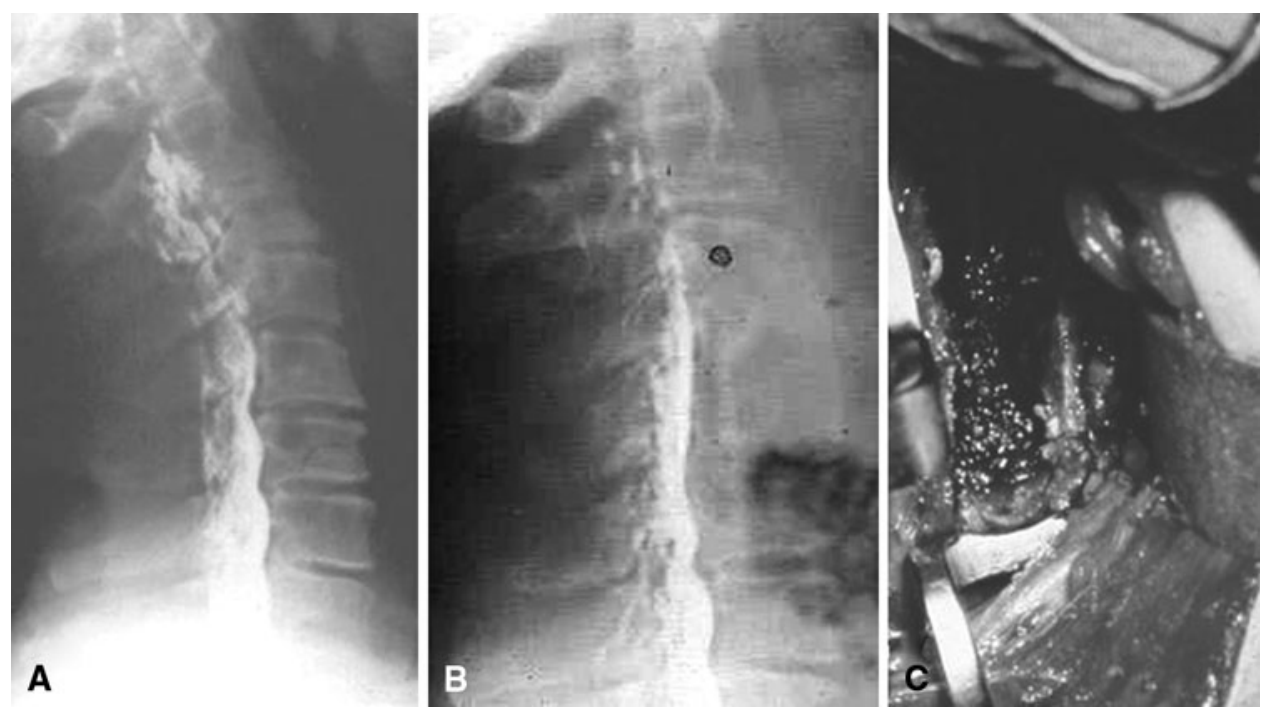

vertebral bodies (up to the posterior longitudinal ligament) and removal of any element of conflict with the spinal cord (Fig. 3). One of the key requirements of this technique was adequate "distraction" to restore lordosis, which was accomplished with a custom-made distractor leading to the development of similar commercial devices.

In 1963, Jung et al. [44, 45] described the surgical approach to the treatment of the Neri [57]-Barrè [4]-Lieou [51] syndrome, a disease left untreated surgically since its discovery in the 1920s. The clinical symptoms ranged from a broad spectrum of osteoarticular (neck pain with or without root signs) and neurovascular symptoms (headache, auricular signs with vertigo, nystagmus, hypoacusia, retro-orbital pain, and photophobic diplopia). Characteristic of the disease is the presence of intervertebral disc degeneration with the presence of osteophytes arising from the uncovertebral joint that impinge over the vertebral artery. This footprint over the vertebral artery could be visualized with arteriography. The first "anterolateral freeing approach" was performed by Jung in Strasbourg in 1963 [44]. This surgery to the "uncodiskalradicular carrefour" consisted of three successive steps, each of which could constitute an operation, namely transversectomy, uncusectomy, and uncoforaminectomy.

At the same time, some continued to prefer the posterior laminectomy to treat degenerative cervical spinal stenosis at multiple levels [21]. In 1973 in Japan, Oyama and Hattori [60] first introduced the laminoplasty to prevent postlaminectomy invasion of the laminectomy membrane. This procedure has not been widely accepted because of the technical difficulties of the operation, related to the thinning of the entire laminae to perform a Z-plasty at each level, leading to long operative times, and high blood loss [21]. To avoid these problems and prevent postlaminectomy instability with consequent malalignment and the rigidity subsequent to fusion, a new surgical technique called "expansive open-door lamino-plasty" was devised by Hirabayashi [41] in 1977 to replace ordinary laminectomy of the cervical spine [42]. This idea came from Hirabayashi's observation of the pulsation of the dura mater at the open-door stage of the laminectomy before removing the laminae "en bloc." It has become the treatment of choice for patients affected by multilevel ossification of the posterior longitudinal ligament disease. Since then, several laminoplasty techniques have been described and currently used as one of the surgeon's tools for posterior decompression surgery [43, 85].

\section{Cervical Fusion and the Development of Current Instrumentations}

Clinically relevant spinal instability is controversial and still not well understood. White and Panjabi defined clinical instability of the spine as the "loss of the spine's ability to maintain its patterns of displacement under physiologic loads so there is no initial or additional neurologic deficit, no major deformity, and no incapacitating pain" [56]. Restoring spinal stability and preventing further neurologic deficits have led surgeons to find a way to stabilize the spine since the end of the 19th century. In December 1890, Hadra [37] first used a silver wire loop to fix the spine for instability secondary to a fracture-dislocation of a cervical spine in a man 30 years of age showing progressive neurologic deterioration. He further extended the indications to Pott's disease.

Lange [50] treated patients with tuberculous spondylitis in the early 1900s. In his procedure, 4-mm steel wires were anchored to the spinous processes and attached to steel rods bilaterally to treat a progressive tuberculosis-induced 
kyphotic deformity. Inflammation and infection from the metal wires impelled him to perform a series of animal studies, seeking an alternative to the wires he considered harmful. In 1908, he used 5-mm tin-coated wires with blunted end knobs and supplementary paraffin-coated silk sutures, yielding less morbidity and presumably improved stability and faster healing in comparison with brace therapy alone.

Fusion techniques were developed at the beginning of the 20th century from the methods of Hibbs [39] and Albee [2]. The Hibbs technique included fusion of the spinous processes and intervertebral joints. The spinous processes were partially osteotomized at their bases and folded down; the cartilage of the intervertebral joints was removed to allow for the apposition of denuded bone (as done for limb joints). Albee performed his technique to fuse the spine in 1909 on patients with Pott's disease. In his technique, the spinous process was split in two and a tibial cortical graft was inserted in the two clefts. In the same paper, he expressed some concerns on the use of silver wires and screws placed through the bone, since he found these broken and moved to the surrounding soft tissues or out of the bone. He was also concerned about the danger of sepsis due to buried metal and considered bone graft preferable to the internal metal spinal splint of Lange [50]. De Quervain and Hoessly [25] of Berne and Basel published a report of a fusion operation at the cervical spine in December 1911. They operated on a patient with dislocation of the fifth over the sixth vertebra and performed a fusion with the use of a portion of the spinous process of the scapula as a bone graft. Mixter and Osgood in 1910 described a method in which they passed a suture under the posterior arch of the atlas and tied it down, over the spinous process of $\mathrm{C} 2$, the basis for subsequent Gallie technique of posterior $\mathrm{C} 1-\mathrm{C} 2$ sublaminar wire fixation with the use of steel wire described in 1939 [34]. In the Gallie technique, a single autograft harvested from the iliac crest was notched inferiorly and placed over the $\mathrm{C} 2$ spinous process and leaned against the posterior arch of $\mathrm{C} 1$. The graft was held in place by a sublaminar wire that passed beneath the arch of $\mathrm{C} 1$ and then wrapped around the spinous process of C2. This technique remained unsurpassed up to the 1980 s and is still frequently used today.

Other wiring techniques were described by Rogers [68] in 1942. Rogers, a former editor of The Journal of Bone and Joint Surgery, later described stabilizing the spine with bone grafts wired to the lamina of the injured segments and a spinous wiring technique [69]. Subsequent techniques [3] were described by Robinson and Southwick [65] and Bohlman [5]. In the technique of Robinson and Southwick, facet fusion of the subaxial cervical spine provided stability after decompressive laminectomy for cervical spinal injury. Their procedure has been utilized in one-stage posterior decompression and fixation procedures, for stabilization after previously performed laminectomy procedures, and for fixation of unstable conditions in which a deficient spinous process has been used as a stabilizing anchor in the cervical spine. The Bohlman triple-wire fixation technique was a modification of the Rogers technique to stabilize a single or multilevel site of segmental instability. In this interspinous wiring method, wires were passed through drilled-out holes in the spinous processes. Additional wires were then passed through the holes and threaded through corticocancellous iliac crest bone grafts. The two wires were tightened to secure the bone grafts against the decorticated spinous processes and laminae on each side. In 1977, Callahan et al. [12] described facet wiring by making holes at the facet joints and securing bone grafts to the facet joints for instability after laminectomy. In this technique, the bottom and top parts of the bone graft also had to be fixed to the first available spinous processes. Later, this technique was improved with the use of contoured threaded compression rods from Harrington instrumentation [55].

In 1975, Tucker [81] described the use of Halifax interlaminar clamps for posterior $\mathrm{C} 1-\mathrm{C} 2$ fusion. As in wiring techniques, the presence of intact laminae at the fusion level was required. The clamps were hooked over the leading and trailing laminar edges. Then screws were applied and the clamps were tightened together. An autologous graft could be interposed between the two spinous processes to prevent hyperextension and enhance fusion. Later, Magerl et al. [53] in 1987 published an alternative C1-C2 fixation by passing threaded screws across the atlantoaxial facet joints, ending in the lateral mass of $\mathrm{C} 1$.

Severe spinal instability, particularly that associated with tumor surgery and/or in patients with marked osteopenia associated with inflammatory spinal diseases, reportedly benefits from the use of acrylic cement to reinforce posterior structures. In 1959, Knight [48] described five patients with cervical spondylosis, chronic fracture-dislocation, and atlantoaxial subluxation in rheumatoid arthritis whose cervical spine he fixed with acrylic cement. Scoville et al. [73] in 1967 reported use of methylmethacrylate in patients with metastatic tumors of the cervical spine and spinal cord compression. They filled the anterior vertebral-body defects with methacrylate, without intending it as internal fixation. In 1972, Kelly et al. [47] described their experience with seven patients in whom methacrylate was used to stabilize a fusion of the first and second cervical vertebrae for atlantoaxial subluxation. Clark et al. [15] subsequently reported stabilization of the cervical spine with methacrylate in 52 patients without intraoperative complications. None of these patients had postoperative external orthoses. Only five patients had local postoperative complications such as wound hematoma or dehiscence. Denaro [20] suggested adjunctive stabilization with methacrylate in patients with cervical 
metastases and poor prognosis. He described a variation of the technique where, after exposure of the spinous process and laminae, Kirschner wires were introduced transcutaneously at a few centimeters' distance from the midline through the spinolaminal junction. Then, wires were passed in a figure of eight to pull the spinous processes together. Finally, acrylic bone cement was added and molded to the laminae and spinous processes enclosing the wires. A similar technique was used to stabilize the spine of patients with ankylosing spondylitis after posterior osteotomy before the introduction of screw-based systems [76, 82].

The modern era of cervical spine surgery in treatment of cervical instability began with the reports of Roy-Camille $[70,72]$ who treated spinal instability with plates and screws inserted in the lateral masses. He designed cervical lateral mass plates with 13-mm distance holes and different lengths. The main indications for spinal fixation were fractures and dislocations, tumors, congenital malformations, and rheumatoid disease. The original Roy-Camille procedure for managing cervical instability was modified by Magerl, Anderson, and An [86]. These surgeons' techniques differ in the entrance point for screw insertion and screw trajectory. Other plates were further developed by Louis, Fuentes, and Magerl [53]. In an effort to apply precise screw placement and realignment, the screw-androd systems were developed between the late 1980s and the 1990 s, with the aim of treating complex spinal abnormalities, such as those occurring in severe degenerative spondylosis or trauma that were difficult to manage with lateral mass plating system [58]. In 1994, Abumi et al. [1] introduced and tested cervical pedicle screws as an alternative method for posterior cervical instrumentation.

Contemporaneously with the development of posterior plates, anterior plates were developed to treat instability after anterior reconstructive procedures in patients affected by trauma or tumor at the anterior spine. More recently, such plates have been used to provide primary stability in conjunction with other fusion constructs that do not provide such stability. The originally used metal plates and screws were those developed for long-bone surgery [23]. These plates were unable to prevent rotation in the area of fusion, since these only had a line of screw holes, and plate loosening tended to occur. Later, plates with two lines of screw holes were developed such as the ASFI [59]. Senegas and Gauzere [74], Strehli [80], Fuentes and Benezech [33], and Caspar et al. [13] have also developed plates to allow exact positioning of the screws.

\section{Occipitocervical Instability}

The treatment of occipitocervical instability benefited from the improved fusion techniques and development of posterior instrumentation. The first report of occipitocervical stabilization was by Foerster [31] in 1927 with the use of a fibular graft. Grafting techniques supplemented the natural repair of more traditional bone fusion techniques: to improve the chances of bony fusion, the graft was either wired or directly fixed to the occiput by the use of screws [14]. Surgeons have employed several fixation methods in the occipitocervical region, including wires, rods, plates, screws, and polymethylmethacrylate in an effort to achieve stability even in the absence of evident bony fusion as might be the case in patients with rheumatoid arthritis or poor metabolic capacity [36]. Newer instrumentation systems together with proper bone grafting techniques have become crucial to this surgery, providing immediate stability and promoting bone healing, integration of the implant, and proper fusion. The modern design of contoured plates and screws systems allowed for primary stability in this problematic region: this big achievement was the result of the efforts by Roy-Camille et al. [71] and Grob et al. [36]. Grob designed the "Y" plates that provided stable fixation over the occiput with a single central plate anchored to the outer cortex (where the width is bigger, thus allowing for more solid anchoring). Screw insertion in this site is safe and is reportedly complicated by meningeal lesion in a few cases [20, 22]. The two distal diverging branches are moldable and secured to the lateral masses posteriorly. Other instrumentation systems commercially available allow for anchoring to the skull with hooks, which are connected to the longitudinal bars and secured distally with screws at the lateral masses and/or laminar hooks at the $\mathrm{C} 2-\mathrm{C} 4$ segment. Roy-Camille plates are "L" shaped and are designed to allow safe screw anchoring to the occiput and the lateral masses of the lower cervical spine.

\section{Discussion}

Through our historical review, we mainly observed how management of the degenerative spine has evolved from decompressive surgery to the concept of direct removal of the cause of the conflict with the neural structures. This passage was helped by improved surgical exposures and instrumentation. The role of fixation in actual or potential spinal instability has been a continuous field of study that allowed the development of more effective fusion techniques and implementation of instrumentation technologies. In the last century, spinal surgeons created the bases for actual nonfusion technologies and surgical techniques, even though adjacent-segment degeneration was not considered an issue up to recent years.

We recognize limitations of our review. First, our selection of articles reflects a singular point of view. 
We realize others could perform similar queries and select differing papers. We do not believe, however, this would affect our conclusions regarding the key points.

Our review describes the evolution of anterior surgery in degenerative disc disease. Despite our efforts, we found no mention of degeneration adjacent to a previous fusion except in the comments of Scoville regarding the work of Cloward in 1959 [75], preceding his colleagues of more than 20 years. Boni and Denaro [7] discussed this issue in 1982 but considered degeneration adjacent to a fusion at the cervical spine as clinically irrelevant. This was later confirmed by Hilibrand et al. [40], who highlighted the role of natural history of the degenerated disc adjacent to the fused vertebrae, and by other authors [27], who outlined the role of postoperative cervical sagittal alignment in determining the accelerated degeneration of the disc adjacent to a fusion.

Whatever the future of this surgery, newer techniques will take inspiration from the efforts and outstanding contributions of those pioneering surgeons of the last 150 years who improved our understanding of cervical spinal disorders and explored the potential of surgery at the cervical spine.

The history of cervical spine surgery must be understood in terms of the evolution in surgical techniques and how the surgeons understood cervical biomechanics. Studies are still required to better understand spinal biomechanics and the cascade of myelopathic disease. The ongoing debate of whether degeneration adjacent to a previous fusion is clinically important and whether cervical spine arthroplasty implants protect against such degeneration require future prospective cohort studies.

Acknowledgment We thank Prof Roberta Aronica for English revision of this paper.

\section{References}

1. Abumi K, Itoh H, Taneichi H, Kaneda K. Transpedicular screw fixation for traumatic lesions of the middle and lower cervical spine: description of the techniques and preliminary report. J Spinal Disord. 1994;7:19-28.

2. Albee FH. Transplantation of portions of the tibia into the spine for Pott's disease: a preliminary report. JAMA. 1911;57:885.

3. An H, Cooper M. Cervical spine instrumentation. In: An H, ed. Principles and Techniques of Spine Surgery. Philadelphia, PA: Williams \& Wilkins; 1998.

4. Barrè J. Posterior Sympathic Cervical Syndrome; the role of the vertebral nerve and of its origins in its genesis; the common causes of irritations of the vertebral nerve; chronic cervical arthritis [in French]. Rev O.N.O. 1926;4:65-70.

5. Bohlman HH. Acute fractures and dislocations of the cervical spine: an analysis of three hundred hospitalized patients and review of the literature. J Bone Joint Surg Am. 1979;61:11191142 .
6. Boni M, Cherubino P, Denaro V, Benazzo F. Multiple subtotal somatectomy: technique and evaluation of a series of 39 cases. Spine (Phila Pa 1976). 1984;9:358-362.

7. Boni M, Denaro V. Surgical treatment of cervical arthrosis: follow-up review (2-13 years) of the 1 st 100 cases operated on by anterior approach [in French]. Rev Chir Orthop Reparatrice Appar Mot. 1982;68:269-280.

8. Boni M, Di Guglielmo L, Denaro V. CT evaluation of the multiple subtotal somatectomy results. In: Kehr P, Weidner A, eds. Cervical Spine. Vienna, Austria: Springer-Verlag; 1987:124-130.

9. Brain R, Wilkinson M. The association of cervical spondylosis and disseminated sclerosis. Brain. 1952;80:456-464.

10. Brain L, Wilkinson M. Cervical Spondylosis and Other Disorders of the Cervical Spine. London, UK: William Heinemann; 1967.

11. Calandriello B. Trattamento chirurgico della spondilite. Paper presented at Relazioni al XLV congresso della Società Italiana di Ortopedia e Traumatologia: Indirizzi odierni nel trattamento della tubercolosi osteoarticolare. October 26-29, 1960; Florence, Italy.

12. Callahan RA, Johnson RM, Margolis RN, Keggi KJ, Albright JA, Southwick WO. Cervical facet fusion for control of instability following laminectomy. J Bone Joint Surg Am. 1977;59:9911002.

13. Caspar W, Barbier DD, Klara PM. Experimental and clinical studies: anterior cervical fusion and Caspar plate stabilization for cervical trauma. Neurosurgery. 1989;25:491-502.

14. Castaing J, Gouaze A, Plisson JL. Technique of occipito-cervical fusion through the use of an iliac crest bone graft screwed into the occipital bone [in French]. Rev Chir Orthop Reparatrice Appar Mot. 1963;49:123-127.

15. Clark CR, Keggi KJ, Panjabi MM. Methylmethacrylate stabilization of the cervical spine. J Bone Joint Surg Am. 1984;66: $40-46$.

16. Cloward RB. The anterior approach for removal of ruptured cervical disks. J Neurosurg. 1958;15:602-617.

17. Codivilla A. Sulla cura chirurgica delle paralisi radicolari del plesso brachiale. In: Putti V, ed. Scritti medici di Alessandro Codivilla. Pubblicati dall'Istituto Ortopedico Rizzoli. Vol Archivio ed atti della società italiana di chirurgia. XX adunanza, 1907. Bologna, Italy: Licinio Cappelli Editore; 1907:902-904.

18. Cummins BH, Robertson JT, Gill SS. Surgical experience with an implanted artificial cervical joint. J Neurosurg. 1998;88:943-948.

19. De Ande JR, MacNab I. Anterior occipitocervical fusion using an extra-pharyngeal exposure. J Bone Joint Surg Am. 1969;51: $1621-1626$.

20. Denaro V. Treatment of metastases and systemic tumors of the cervical spine. Neuro-orthopaedics. 1988;6:101-110.

21. Denaro V. Stenosis of the Cervical Spine. Berlin, Germany: Springer-Verlag; 1991.

22. Denaro V. Surgical management of cervical myelopathy according to the Boni-Denaro technique. In: Kehr P, ed. Rachis cervical dégénératif et traumatique, Cahiers d'enseignement de la SOFCOT. Paris, France: Expansion Scientifique Francaise; 1994:174-182.

23. Denaro V, Denaro L, Di Martino A, Longo U, Maffulli N. Degenerative disk disease. In: Denaro L, D’Avella D, Denaro V, eds. Pitfalls in Cervical Spine Surgery (Avoidance and Management of Complications). Berlin, Germany: Springer-Verlag; 2010:121-163.

24. Denaro V, Papalia R, Denaro L, Di Martino A, Maffulli N. Cervical spinal disc replacement. J Bone Joint Surg Br. 2009;91: 713-719.

25. De Quervain F, Hoessly H. Operative immobilization of the spine. Surg Gyn Obstet. 1917;24:428-436.

26. Elsberg C. Tumors of the Spinal Cord and the Symptoms of Irritation and Compression of the Spinal Cord and Nerve Roots: 
Pathology, Symptomatology, Diagnosis and Treatment. New York, NY: Paul B. Hoeber; 1925.

27. Faldini C, Leonetti D, Nanni M, Di Martino A, Denaro L, Denaro V, Giannini S. Cervical disc herniation and cervical spondylosis surgically treated by Cloward procedure: a 10-year-minimum follow-up study. J Orthop Traumatol. 2010;11:99-103.

28. Fernström U. Arthroplasty with intercorporal endoprothesis in herniated disc and in painful disc. Acta Chir Scand Suppl. 1966;357:154-159.

29. Fineschi G. Statistical observation of 132 cervical disc herniations [in Italian]. Arch Putti. 1961;15:1-10.

30. Fineschi G. Clinica e terapia delle protrusioni del tratto cervicale. Paper presented at Atti $51^{\circ}$ congresso della Società Italiana di Ortopedia e Traumatologia: Le protrusioni posteriori del disco intervertebrale. October 22-25, 1966; Catania, Italy.

31. Foerster O. Die Feitungsbajnen des Schmerzgefuls. Berlin, Germany: Urban and Schwarzenburg; 1927:266.

32. Frykholm R. Lower cervical vertebrae and intervertebral discs: surgical anatomy and pathology. Acta Chir Scand. 1951;101: 345-359.

33. Fuentes JM, Benezech J. Les osteosyntheses rachidiennes en neurochirurgie. Montpellier, France: La clinique recherche de Montpellier; 1986.

34. Gallie WE. Fractures and dislocations of cervical spine. Am $J$ Surg. 1939;46:495-499.

35. Gowers WR, ed. Diseases of the Nervous System. 2nd ed. London, UK: Churchill; 1892.

36. Grob D, Dvorak J, Panjabi M, Froehlich M, Hayek J. Posterior occipitocervical fusion: a preliminary report of a new technique. Spine (Phila Pa 1976). 1991;16(3 Suppl):S17-S24.

37. Hadra BE. Wiring the spinous processes in fracture and Pott's disease. Trans Am Orthop Assoc. 1891;4:206-210.

38. Henry A. Extensile Exposure. Edinburgh, UK: Livingstone; 1957.

39. Hibbs RA. An operation for progressive spinal deformities: a preliminary report of three cases from the service of the orthopaedic hospital. 1911. Clin Orthop Relat Res. 2007;460:17-20.

40. Hilibrand AS, Carlson GD, Palumbo MA, Jones PK, Bohlman HY. Radiculopathy and myelopathy at segments adjacent to the site of a previous anterior cervical arthrodesis. J Bone Joint Surg Am. 1999;81:519-528.

41. Hirabayashi K. Expansive open-door laminoplasty for cervical spondylotic myelopathy [in Japanese]. Shujutsu. 1978;32:11591163

42. Hirabayashi K, Satomi K. The posterior and anterior operation in treatment of cervical disk lesions including cervical spondylosis: a long term follow-up study [in Japanese]. Chubu Seisaishi. 1972;15:786-788.

43. Hirabayashi K, Satomi K. Expansive open-door laminoplasty. In: Denaro V, ed. Stenosis of the Cervical Spine. Berlin, Germany: Springer-Verlag; 1989:264-278.

44. Jung A. Resection of the unco-vertebral joint and opening of the foramen via an anterior approach for the treatment of the cervicobrachial neuralgia: surgical technique [in French]. Mem Acad Chir (Paris). 1963;89:11-13.

45. Jung A, Vierling JP. Surgical treatment of a vertebral artery syndrome caused by inferior cervical arthrosis [in French]. Ann Chir Thorac Cardiovasc. 1963;2:462-464.

46. Kahn EA. The role of dentate ligaments in spinal cord compression and the syndrome of lateral sclerosis. J Neurosurg. 1947; 4:191-199.

47. Kelly DJ, Eben AJ, Davis CJ, Smith J. Acrylic fixation of atlantoaxial dislocations: technical note. J Neurosurg. 1972;36:366-371.

48. Knight G. Paraspinal acrylic inlays in the treatment of cervical and lumbar spondylosis and other conditions. Lancet. 1959;2:147-149.

49. Kocker T. Surgery of the pharynx. In: Kocker T, ed. Operative Surgery. London, UK: Black; 1911.
50. Lange F. The classic. 1910. Support for the spondylitic spine by means of buried steel bars, attached to the vertebrae. Clin Orthop Relat Res. 1986;203:3-6.

51. Lieou Y. Syndrome sympathique cervical posterieur et arthrite chroniqu de la colonne cervicale: etude clinique et radiologique [thesis]. Strasbourg, France: University of Strasbourg; 1928.

52. Lysell E. Motion in the cervical spine: an experimental study on autopsy specimens. Acta Orthop Scand. 1969;Suppl 123:1-61

53. Magerl F, Grob D, Seeman P. Stable dorsal fusion of the cervical spine [C2-Th1] using hook plates. In: Kehr P, Weidner A, eds. Cervical Spine I. Vienna, Austria: Springer-Verlag; 1987:127.

54. McKenzie AH. Fernstrom intervertebral disc arthroplasty: a longterm evaluation. Orthop Int. 1995;3:313-324.

55. Murphy MJ, Ogden JA, Southwick WO. Spinal stabilization in acute spinal injuries. Surg Clin North Am. 1980;60:1035-1047.

56. Naderi S, Andalkar N, Benzel EC. History of spine biomechanics: Part II-from the Renaissance to the 20th century. Neurosurgery. 2007;60:392-403.

57. Neri V. Cerebral syndrome sympathetic cervical spine [in Italian]. Boll Soc Med 1924;96:382-388.

58. Omeis I, DeMattia JA, Hillard VH, Murali R, Das K. History of instrumentation for stabilization of the subaxial cervical spine. Neurosurg Focus. 2004;16:E10.

59. Orozco Delclos R, Llovet-Tapies J. Osteosynthesis in the treatment of fractures of the cervical spine: technical note [in Spanish]. Revista de Ortopedia y Traumatologia. 1970;14:285288.

60. Oyama M, Hattori S. A new method of cervical laminectomy. Chubu Seisaishi. 1973;16:792-794.

61. Peet MM, Echols D. Herniation of the nucleus pulposus: cause of compression of the spinal cord. Arch Neurol Psychiatry. 1932;32: 925-932.

62. Riley LH Jr. Surgical approach to anterior structures of the cervical spine. Clin Orthop Relat Res. 1973;91:16-20.

63. Riskin DJ, Longaker MT, Gertner M, Krummel TM. Innovation in surgery: a historical perspective. Ann Surg. 2006;244:686-693.

64. Robinson RA, Smith GW. Anterolateral cervical disc removal and interbody fusion for cervical disc syndrome. Bull John Hopkins Hosp. 1955;96:223-224.

65. Robinson RA, Southwick WO. Indications and technics for early stabilization of the neck in some fracture dislocations of cervical spine. South Med J. 1960;53:565-579.

66. Robinson R, Walker A, Ferlinc D, Wiedìcking D. The results of an anterior interbody fusion of the cervical spine. J Bone Joint Surg Am. 1962;44:1569-1587.

67. Rogers L. The treatment of cervical spondylotic myelopathy by mobilisation of the cervical cord into an enlarged spinal canal. J Neurosurg. 1961;43:490-492.

68. Rogers WA. Treatment of fractures and dislocations of the cervical spine. J Bone Joint Surg Am. 1942;24:145-248.

69. Rogers WA. Fractures and dislocations of the cervical spine: an end-result study. J Bone Joint Surg Am. 1957;39:341-376.

70. Roy-Camille R, Saillant G, Mazel C. et al. Rachis cervical traumatique non neurologique. In: Roy-Camille R, ed. leres journees d'orthopedie de la Pitie. Paris, France: Masson; 1979.

71. Roy-Camille R, Gagna G, Lazennec J. L'arthrodese occipitocervicale. In: Roy-Camille R, ed. 5eme journees d'orthopedie de la Pitie: Rachis cervical superieur. Paris, France: Masson; 1986.

72. Roy-Camille R, Saillant G. Surgery of the cervical spine. 3. Complex fractures of the lower cervical spine. Tetraplegia [in French]. Nouv Presse Med. 1972;1:2707-2709.

73. Scoville WB, Palmer AH, Samra K, Chong G. The use of acrylic plastic for vertebral replacement or fixation in metastatic disease of the spine: technical note. J Neurosurg. 1967;267:274-279.

74. Senegas J, Gauzere JM. Unstable fractures of the spine. IV. Stabilization methods and their results. B. Surgical methods. 6 . 
Treatment of cervical lesions by anterior approach [in French]. Rev Chir Orthop. 1977;63:466-469.

75. Sherk HH, Bucholz RW, Hamilton JJ, eds. Getting It Straight: A History of American Orthopaedics. Rosemont, IL: The American Academy of Orthopaedic Surgeons; 2008. 39

76. Simmons EH. The surgical correction of flexion deformity of the cervical spine in ankylosing spondylitis. Clin Orthop Relat Res. 1972;86:132-143.

77. Smith GW, Robinson RA. The treatment of certain cervical spine disorders by anterior removal of the intervertebral disc and interbody fusion. J Bone Joint Surg Am. 1958;40:607-624.

78. Southwick WO, Robinson RA. Surgical approaches to the vertebral bodies in the cervical and lumbar regions. $J$ Bone Joint Surg Am. 1957;39:631-634.

79. Stookey B. Compression of the spinal cord due to ventral extradural cervical chondromas: diagnosis and surgical treatment. Arch Neurol Psychiatry. 1928;20:275-291.

80. Strehli R. Double hole plate fixation of the lower cervical spine. In: Kehr P, Weidner A, eds. Cervical Spine I. Vienna, Austria: Springer-Verlag; 1987:175.
81. Tucker HH. Technical report: method of fixation of subluxed or dislocated cervical spine below C1-C2. Can J Neurol Sci. 1975;2:381-382.

82. Urist MR. Osteotomy of the cervical spine: report of a case of ankylosing rheumatoid spondylitis. J Bone Joint Surg Am. 1958; 41:833-843.

83. Walton GL, Paul WE. Contribution to the study of spinal surgery: one successful and one unsuccessful operation for the removal of tumor. Bost Med Surg J. 1905;153:114-117.

84. Whiteside TE, Kelly RP. Lateral approach to the upper cervical spine for anterior fusion. South Med J. 1966;59:879883.

85. Woods BI, Hohl J, Lee J, Donaldson W 3rd, Kang J. Laminoplasty versus Laminectomy and Fusion for Multilevel Cervical Spondylotic Myelopathy. Clin Orthop Relat Res. 2010 November 19 [Epub ahead of print].

86. Xu R, Haman SP, Ebraheim NA, Yeasting RA. The anatomic relation of lateral mass screws to the spinal nerves: a comparison of the Magerl, Anderson, and An techniques. Spine (Phila Pa 1976). 1999;24:2057-2061. 